\title{
Chart for Flexible Curriculum in terms of Time and Similarity
}

\author{
Manuel Embus, Jesús H. Camacho-Tamayo, María Alejandra Guzmán \\ Faculty of Engineering, Universidad Nacional de Colombia, Colombia
}

\begin{abstract}
Within the framework of the evaluation of curricular reforms made in the programs of the Faculty of Engineering of the Universidad Nacional de Colombia, this proposal is designed as an evaluation tool for a flexible curriculum, to characterize the enrollment behavior of students and their possible relationships with demographics and academic success. The principle consists of plotting the median time and similarity coefficients of each student in the program on the axes of a two-dimensional Cartesian plane. On the X-axis, the time coefficient was plotted, consisting in the relationship between the time proposed by the program curriculum for each course, and the time when the student takes it. On the Y-axis, the similarity coefficient was plotted, consisting in the number of courses that were taken at the time indicated in the curriculum grid. The conclusions suggest that, for the program analyzed, there are no demographic biases. However, the findings of this study suggest that even though students seek to take the proposed curriculum with the highest possible similarity, they spend more time than the estimated to achieve academic success
\end{abstract}

Keywords: Curriculum; Assessment; Time; Similarity 


\section{Introduction}

Internationalization of higher education is forcing engineering programs to look with special care the way of doing self-assessment and obtaining accreditations. One of the critical factors for effectively assessing programs with a flexible curriculum and academic freedom is to measure the time and relationship among the proposed curriculum established by the program, the actual curriculum that each student decides to take, and demographic variables.

The Universidad Nacional de Colombia is the most recognized public University with a presence in the entire country. The main campus is located in Bogotá, where students from all Colombian regions access programs that are far from their hometowns. Since middle education in Colombia has different levels that are highly related to demographic classification (Barón-Rivera \& Bonilla-Mejía, 2014), the University established different admission programs searching equity for all applicants. In this sense, the PEAMA and PAES programs consist of the student taking courses at the nearest location to his or her hometown or reducing the score needed to be admitted, respectively.

However, a significant problem resides in the belief that the current program curriculums have bias related to demographic variables and that these variables are related to the number of semesters to complete the curriculum. For these reasons, it becomes necessary to develop a tool that allows studying the proposed curriculum in terms of similarity and time. This article presents a proposal that allows representing each student's curriculum as a point in a bi-dimensional plot through a classification made with a Matlab® algorithm. This paper takes a look at students of Agricultural Engineering and the pattern in which they take their subjects over time.

\section{Methodology}

In order to assess the flexible curriculum, it was necessary to establish all the information needed for the classification of data for each student. Table 1 summarizes an overview of the information sources, which are, in their entirety, University dependencies that store the databases containing all the data needed for the analysis. It was also needed to define the target population that was stablished as the students that entered the Agricultural Engineering program from 2010 to 2012. Considering the mean number of students admitted per semester, an estimated of three hundred people that take almost fifty courses represent nearly fifteen thousand registries. The process of Extract, Transform, and Load (ETL) is divided into two stages that consist in the depuration of the obtained data and the codification of the different curricula in order to easily compare them with the ones taken by each student. 
Table 1. Records used and their source within the University.

\begin{tabular}{cc}
\hline Source & Variable \\
\hline $\begin{array}{c}\text { National Academic Information Office } \\
\text { (DNINFOA) }\end{array}$ & $\begin{array}{c}\text { Student IDs and sex } \\
\text { Courses taken by each student sort by } \\
\text { typology and semester } \\
\text { National Admissions Office } \\
\text { (DNA) }\end{array}$ \\
Program & Last academic status \\
\hline
\end{tabular}

\subsection{Depurate of registries}

After filtering the information given by DNINFOA, it was necessary to define the adequate number of academic periods for each year. This consideration is specific to the University due to the possibility of taking courses between semesters in a short inter-semester period that allows the students to take one course during one month of dedicated work. These courses are an opportunity to take courses of upper semesters or to repeat the failed ones. Therefore, all the courses taken in the inter-semester period were assigned to the previous one in order to make a reasonable comparison.

Colombian cities are sorted in thirty-two departments that can be grouped into five regions. Due to the way the DNA registers the birthplace and the different changes in that codification through the years, a region standardization was needed for analyzing this information accurately.

\subsection{Codification of the curriculum}

Three curricula were examined due to the different changes that occur during the periods of analysis. The first curriculum was stablished in 2010 (Dirección de Área Curricular de Ingeniería Civil y Agrícola, 2010). In the second one, created in 2013, it was necessary to move the electrotechnology course to the eighth semester (Dirección de Área Curricular de Ingeniería Civil y Agrícola, 2013). The last one was implemented in 2016 (Equipo Directivo de la Facultad de Ingeniería, 2015). Each course was defined as an object that has the following attributes: code, name, and a defined semester to be taken for the students of each curriculum. 


\subsection{Defining the coding algorithm to analyze the information}

Two tables were defined: (1) Students that contains the ID, admission period, sex and last academic status and (2) Courses that has the student ID, the semester in which the student took the course, a course code and name, a typology, and the Total number of courses taken by the student. For each student, the flow of actions is represented in the following pseudo code:

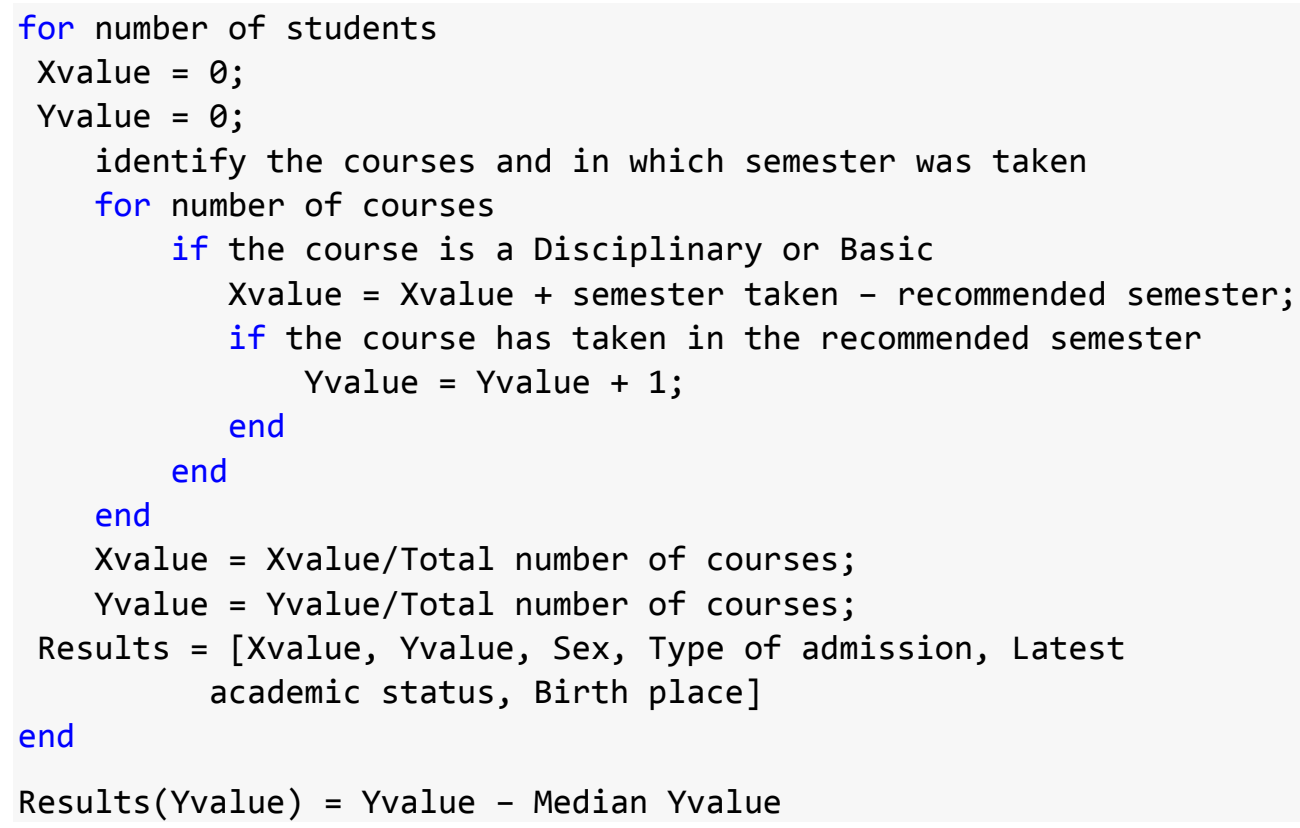

The scope of the study was limited to disciplinary (core) and basic courses, considering that changes in the order of the elective courses represent no significant differences in the figures. If the student decided to take more elective courses in one semester, this will be reflected in an increase of the Xvalue caused by the delay.

Figure 1 and Figure 2 show the way to interpret the results obtained in the bi-dimensional plot. The $\mathrm{Y}$ values increase in terms of the similarity the relationship of similarity between the courses took by the student, and the distribution of courses recommended by the program. The Xvalues represent the evaluated mean of how early or late the students take the courses in their academic career. For example, a student that accomplishes the courses in the same way as proposed in the curriculum and without any delays would be located at the top of the plot (Xvalue $=0$ and Yvalue $=1$ ). 


\begin{tabular}{ll|l|l} 
II Quadrant & I Quadrant \\
\hline High Similarity with the original & & High Similarity with the original \\
\hline curriculum, in lower time, that the & & curriculum, in higher time, that the \\
\hline proposed by the program. & & proposed by the program. \\
\hline Lack of Similarity with the original & & Lack of Similarity with the original \\
\hline curriculum, in lower time, that the & & curriculum, in higher time, that the \\
\hline proposed by the program. & & proposed by the program. \\
\hline & & \\
\hline
\end{tabular}

Figure 1. How to interpret the results.

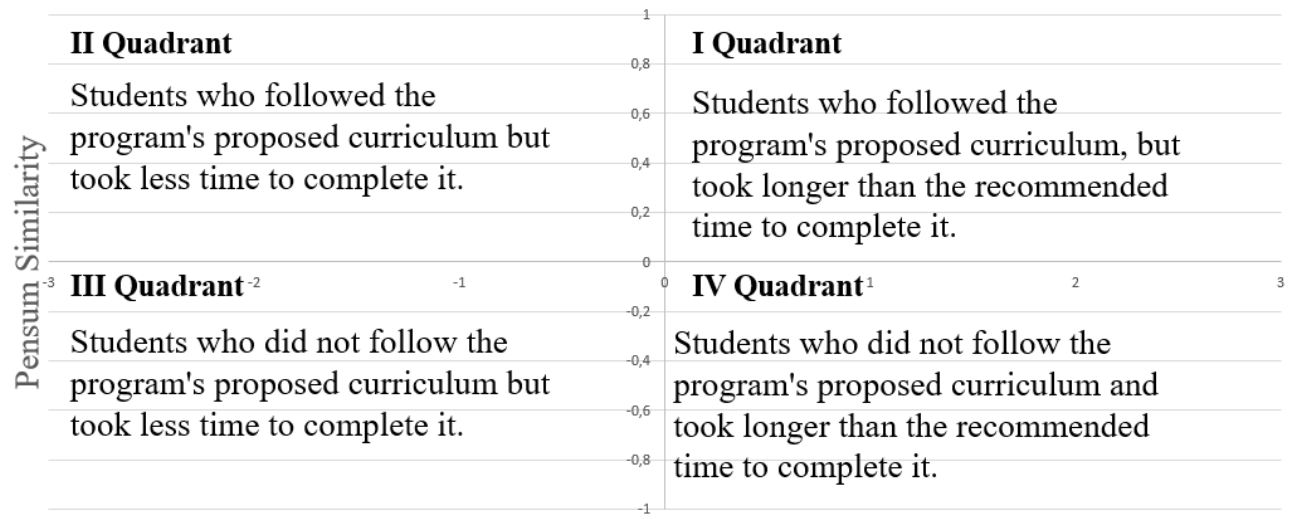

Time Reference

Figure 2 Practical Examples

\section{Results}

The first set of analyses examined the impact of sex and region as is shown in

Figure 3 and Figure 4, respectively. Results obtained indicates that there are no strong relations among the data. However, the entire population reported significantly more courses taken late in comparison with the proposed program curricula. 


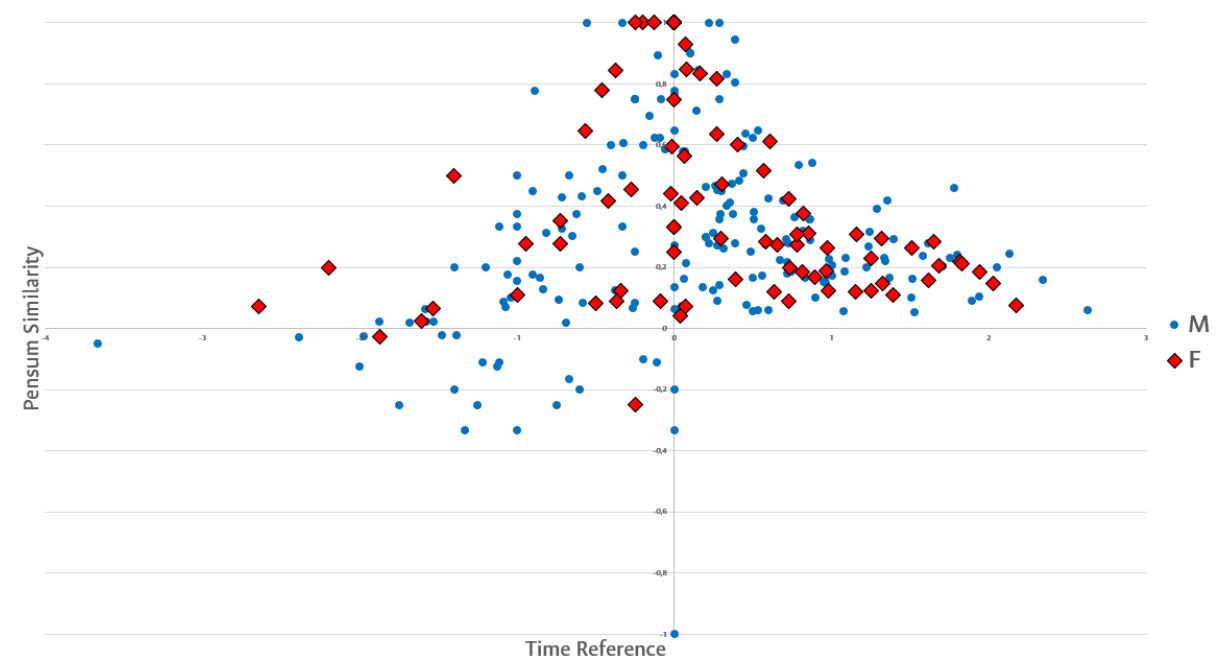

Figure 3. Sex distribution.

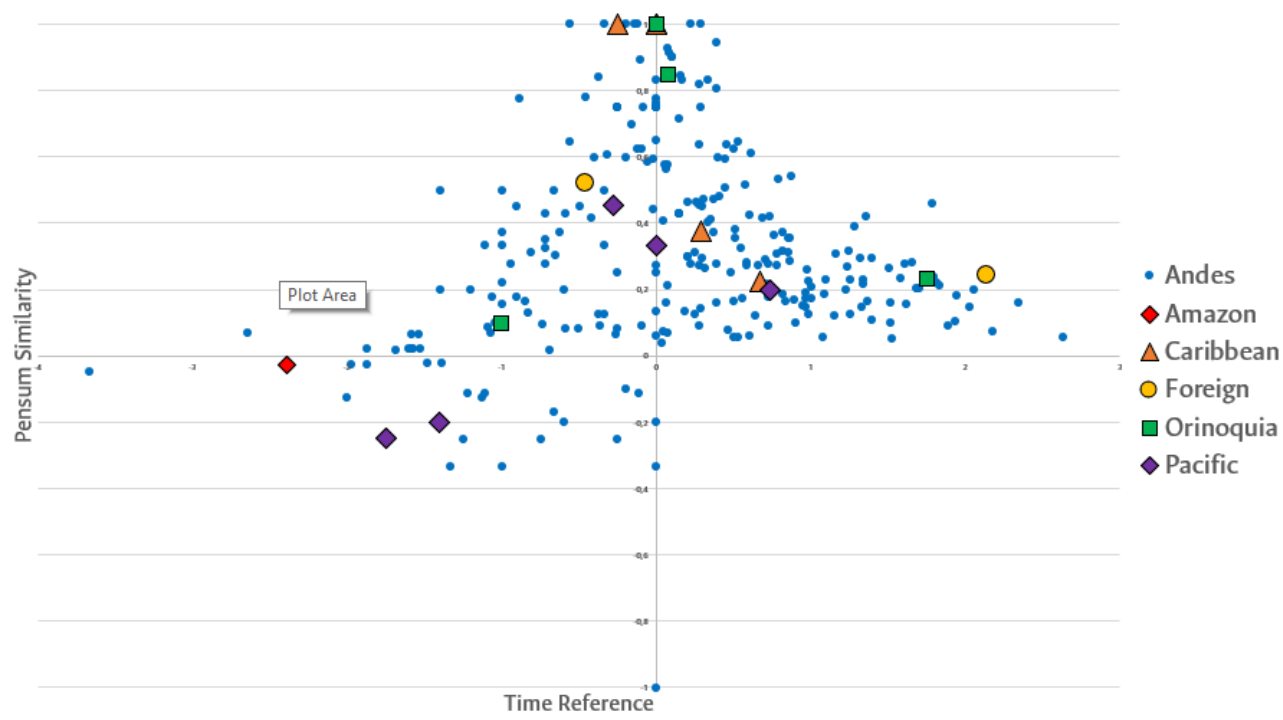

Figure 4. Region of the student hometown

The third plot shown in Figure 5 represents a more specific analysis of the behavior obtained in the previous analysis with demographic data. Academic status indicates that even when the entire population of the study has completed at least the maximum amount of time to finish all the courses, there is still a significant amount of people that is active as undergraduate student and a big part of this group is located in the first quadrant of the cartesian plane. 


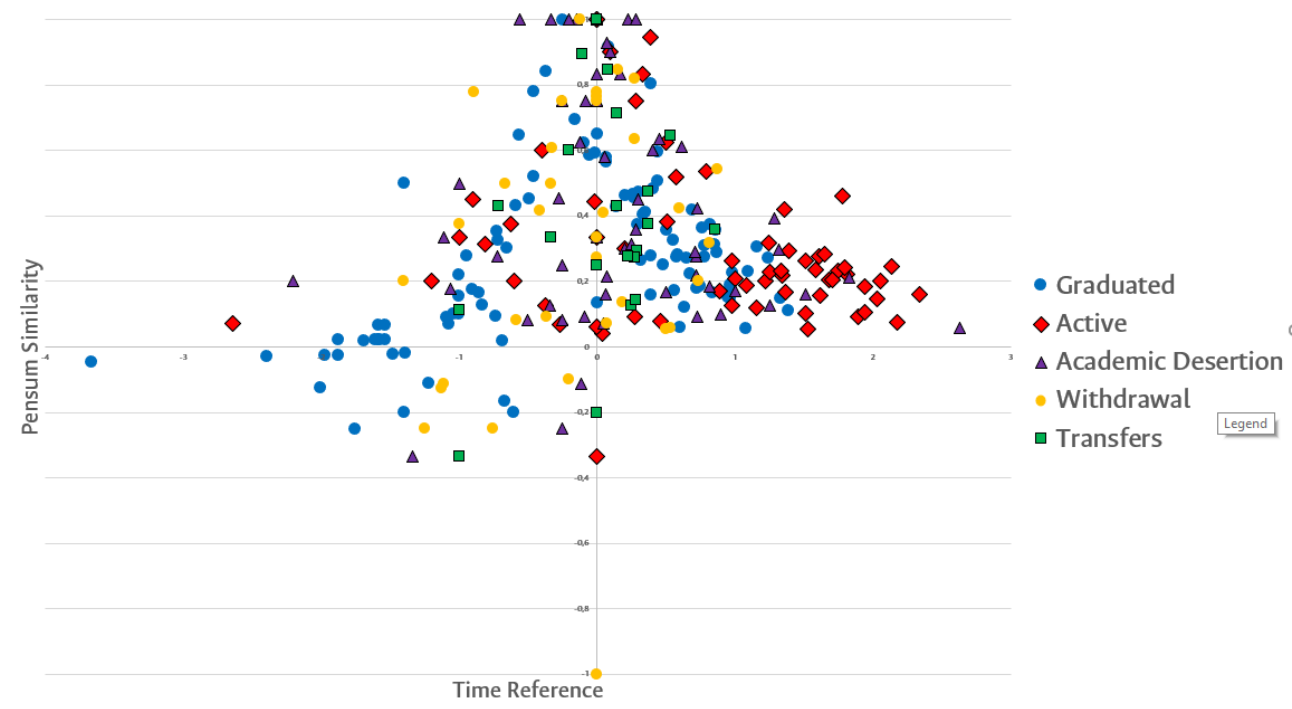

Figure 5. Latest academic status distribution

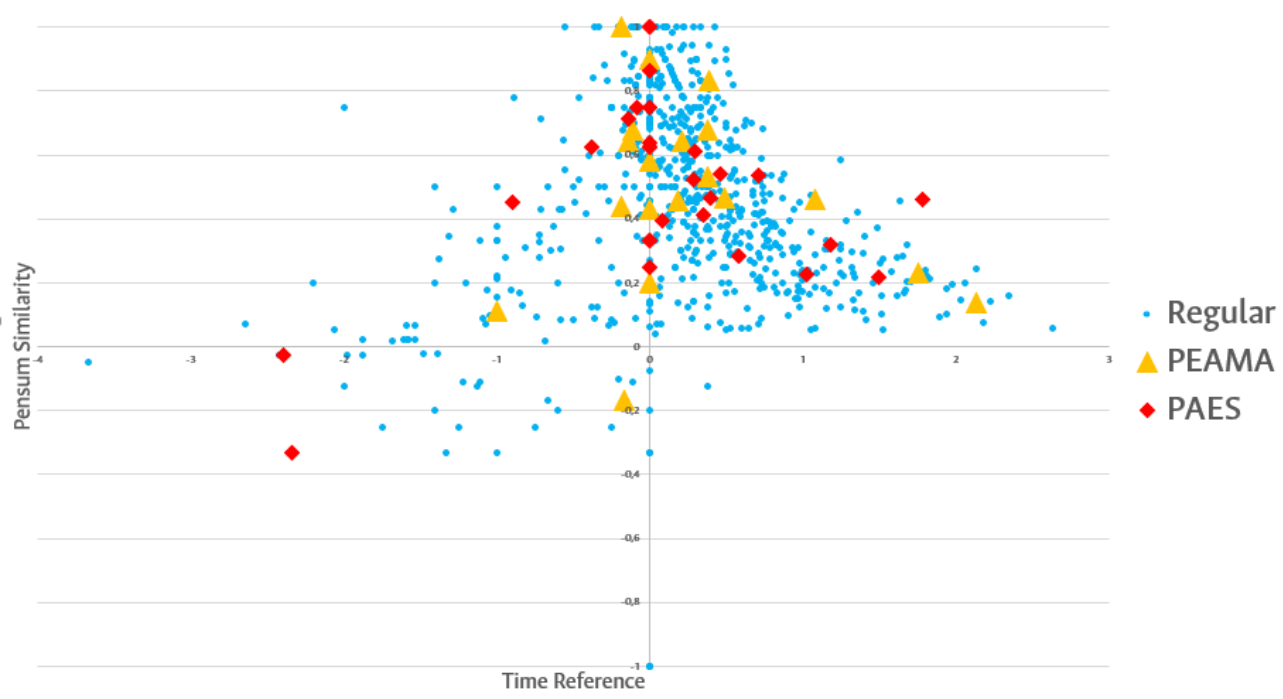

Figure 6. Types of admissions

Due to the low number of students who had a special admission (PAES or PEAMA), it was necessary to make the sample more prominent, as shown in Figure 6. With the new set of data, the tendency to be in the first quadrant is more significant. However, in order to explain the behavior of the students located in the left zone of the plot, this data analysis evidenced that some courses programed for the end of the curriculum, like economy and management, are taken early by the students. 


\section{Conclusions}

The present study was designed to determine possible implications of the way students take their courses in a flexible curriculum. Results have shown that the Agricultural Engineering program has no bias generated by sex, city of origin, or type of admission, this apparent lack of correlation can be attributed to sampling size and sampling bias generated by previous relationships between variables, such as the current ratio of men to women (4:1) and the relation between regular and special admissions (9:1). Nevertheless, the findings of the designed tool still state significant discoveries.

Given the trend to quadrant 1 shown in the results, it became noticeable that students seek to follow the proposed curriculum. However, there is a trend toward zero on the $\mathrm{Y}$ axis, which indicates that there is a slight variation in a small group of subjects. The analysis of the database showed that there is a considerable number of students who decide to take economy courses early despite the recommended time suggested in the curriculum (at the end of their program). However, there are possible explanations and questions that still require further research.

\section{References}

Barón-Rivera, J. D., \& Bonilla-Mejía, L. (2014). Desempeño relativo de los graduados en el área de educación en el examen de Estado del ICFES. Educación y Desarrollo Regional En Colombia. Capítulo 4. Desempeño Relativo de Los Graduados En El Área de Educación En El Examen de Estado Del ICFES. Pág.:131-157. Retrieved from http://repositorio.banrep.gov.co/handle/20.500.12134/6708

Dirección de Área Curricular de Ingeniería Civil y Agrícola. (2010). Plan de estudios Plan de estudios Ingeniería Agrícola Acuerdo 134 de 2010 del Consejo de Facultad de Ingeniería de la Universidad Nacional de Colombia (p. 1). p. 1.

Dirección de Área Curricular de Ingeniería Civil y Agrícola. (2013). Plan de estudios Plan de estudios Ingeniería Agrícola Acuerdo 15 de 2013 del Consejo de Facultad de Ingeniería de la Universidad Nacional de Colombia.

Equipo Directivo de la Facultad de Ingeniería. (2015). Proyecto Educativo del Programa (Vol. 1). Retrieved from http://www.pregrado.unal.edu.co/docs/pep/pep_2_25.pdf 